\title{
Differences in hepatitis $B$ infection rate between ethnic groups in antenatal women in Birmingham, United Kingdom, May 2004 to December 2008
}

M Caley (Michael.caley@warwickshire.nhs.uk)1, T Fowler², S Greatrex³ , A Wood4

1. NHS Warwickshire, Warwick, United Kingdom

2. UK Department of Health, United Kingdom

3. Heart of Birmingham PCT, United Kingdom

4. University of Birmingham, United Kingdom

Citation style for this article:

Caley M, Fowler T, Greatrex S, Wood A. Differences in hepatitis B infection rate between ethnic groups in antenatal women in Birmingham, United Kingdom, May 2004 to December 2008 . Euro Surveill. 2012;17(30):pii=20228. Available online: http://www.eurosurveillance.org/ViewArticle.aspx?Articleld=20228

Article submitted on 11 November 2011 / published on 26 July 2012

Hepatitis B virus (HBV) is a major cause of morbidity and mortality worldwide. Although the United Kingdom (UK) prevalence of HBV is low, it is increasing. There is some evidence that the rate of infection is much higher in some populations living in Britain of non-white ethnicity or who were not born in Britain, compared with the British-born white population. We examined the prevalence of HBV infection in pregnant women through hepatitis B surface antigen (HBsAg) or e-antigen ( $\mathrm{HBeAg}$ ) in Birmingham UK between May 2004 and December 2008 and the effect of ethnicity on the relative risk of infection. There was a significant increase in the number of antenatal HBV infections detected over the study period from 106 cases in 2005 to 161 cases in $2008(p=0.037)$. Women who define themselves as of black African, non-British white and Pakistani ethnicity had a markedly elevated rate of HBV infection (relative risk (RR): 11.25, 5.87 and 2.33 respectively) compared to the England average. Health organisations that serve populations with a high or increasing proportion of women originating from intermediate and high HBV prevalence areas of the world such as Africa, some parts of Europe and Asia, should anticipate a need for perinatal and postnatal prophylaxis to children born to HBV infected mothers.

\section{Introduction}

Hepatitis B virus (HBV) is a major cause of morbidity and mortality worldwide. It is estimated to have affected two billion people, 350 million of which have chronic infection [1]. The overall United Kingdom (UK) prevalence of chronic infection is low ( $1 \%$ ) particularly in pregnant women, however the annual number of hepatitis B notifications in England and Wales is increasing $[1,2]$. Although data on the prevalence of hepatitis $B$ in the UK and the impact of migration patterns are limited, there is some evidence that the rate of infection is much higher in people not born in Britain or of non-white ethnicity compared with the British-born white population reflecting the higher HBV prevalence in their countries of birth or family origin $[3,4]$.

All pregnant women in the UK are offered HBV testing as part of the national antenatal screening programme for infectious diseases. Women are offered HBV testing at their first antenatal appointment, usually at 8-12 weeks of pregnancy.

In the UK, pregnant women with HBV infection are treated based upon the severity of disease, and benefits of reducing viral activity balanced against potential side effects and the unknown teratogenicity of antiviral treatment [5]. These judgements are made by specialist physicians on a case-by-case basis. Vertical transmission of HBV infection occurs in $90 \%$ of pregnancies where the mother is hepatitis $\mathrm{B}$ e-antigen ( $\mathrm{HBeAg}$ ) positive and in about $10 \%$ of pregnancies where the mother is hepatitis B surface antigen ( $\mathrm{HBsAg}$ ) positive, e-antigen negative. More than $90 \%$ of infected infants become chronic carriers [6]. In the UK, babies born to HBV infected mothers should all receive a course of HBV immunisation starting with a first dose of vaccine at birth and three further doses at one, two and twelve months of age. Babies born to highly infectious mothers, this includes those who are positive for $\mathrm{HBeAg}$, also receive hepatitis $B$ immunoglobulin at birth. This regime reduces vertical transmission by $90 \%$ [1]. A booster vaccine at around five years of age is also recommended for those at ongoing risk.

The England average rate of HBV infection in antenatal blood specimens is 350 per 100,000 specimens [7]. Factors that influence prevalence include geographical location of residence and country of birth, with both people residing in urban areas and people born in countries of high prevalence having higher rates of infection $[1,7]$. 
The World Health Organization (WHO) has categorised countries based upon the prevalence of $\mathrm{HBsAg}$ into high (more than $8 \%$ ), intermediate ( 2 to $8 \%$ ) and low (less than 2\%) prevalence countries [1]. The highest rates of HBV infection in low prevalence countries are often in people who immigrate from high prevalence countries $[8,9]$. However those groups at highest risk often have a lower uptake of preventative health services due to language barriers and a lack of awareness $[10,11]$. In immigrants from high prevalence to low prevalence countries, difficulties in mastering the language of the host country has also been found to correlate with poor levels of antenatal care [12]. It is therefore important that antenatal services meet the need of pregnant women infected with HBV and that services adapt as the demographics of the population they serve changes. This paper describes the differences in epidemiology of HBV infection in pregnant women in a large multiethnic city in England.

\section{Methods}

Birmingham is the second largest city in the UK with a population of approximately 1.1 million. Based on 2001 UK census data, where ethnicity is self reported, and other factors affecting population change, it is estimated that $65 \%$ of the population are white British, $20 \%$ are of South Asian ethnicity and about $5 \%$ are from black ethnic groups. Solihull is a neighbouring metropolitan borough that is continuous with Birmingham and has a population of about 220,000 . The Birmingham and Solihull Health Protection Unit receives all notifications of women testing positive for $\mathrm{HBsAg}$ or $\mathrm{HBeAg}$ as part of antenatal screening, who live within the boundary of the Birmingham and Solihull area.

All pregnant women between May 2004 and December 2008 who tested positive for $\mathrm{HBsAg}$ or $\mathrm{HBeAg}$ were identified as cases in this study. All cases were tested for $\mathrm{HBsAg}$. In the vast majority of patients, $\mathrm{HBeAg}$ was tested, although a small number failed to have this test completed. Demographic details were recorded for all cases. Women who were identified as testing positive for HBV by antenatal screening in the time of this study, but who were previously known to have been diagnosed with HBV, were also included in the study. Where women were identified in two or more separate pregnancies during the study period, all pregnancies were included to estimate the level of demand for prevention and treatment services. Repeat pregnancies were excluded from ethnic group rate of infection and relative risk of infection calculations, in order to avoid counting the same cases more than once. Duplicate cases were removed manually. Regression analysis was used to examine the changes over time of the total number of cases per quarter. Differences between the rate of $\mathrm{HBV}$ infection in different ethnic groups were also examined using a chi-squared test.

Ethnicity was self reported by cases, choosing from a predefined list of ethnicity categories. This is the recommended method for identifying ethnicity by the Office for National Statistics (ONS) [13]. Ethnic categories were based on the 2001 census categories [13], but a number of categories were combined to allow meaningful comparisons. Membership of an ethnic category is not defined by place of birth, though this may be a determining factor in peoples' choice of group, but rather the ethnic group a person feels they belong to. Thus a person defining themselves as of black African ethnicity could be born in Africa or born in Britain but be a member of the black African community. The ethnicity categories comprised: (i) 'white British', denoting a person of white ethnicity who considers their ethnic background to be predominantly of British origin, (ii) 'white other', a person of white ethnicity who considers their ethnic origin from a country other than Britain, including the category 'white Irish', (iii) 'black African', (iv) 'black Caribbean', (v) 'black other', a person of black ethnicity who considers their ethnic origin not to be in Africa or Caribbean, (vi) Pakistani, (vii) Chinese, (viii) Bangladeshi, (ix) Indian, (x) 'Asian other', a person of Asian ethnicity who considers their ethnic origin to be from that of a country other than the countries listed above. Ethnicity data was collected using the primary ethnicity identified by the case. There was no capacity to capture dual ethnicity categorisation, and country of birth was not collected.

Denominator data on the ethnicity of all pregnant women was only available for the years 2007 and 2008. The categorisation of ethnicity differed slightly between the HBV infected cases and the denominator data because this information was collected by different organisations. Case data was collected by a questionnaire on epidemiology, which provided a more detailed breakdown of ethnicity, whilst denominator data was collected routinely by maternity services using broader categories as part of usual care. Therefore to calculate the rate of infection in different ethnic groups, it was necessary to merge some ethnicity categories with others. For these purpose the cases with ethnicity categories Chinese, 'black other', 'Asian other' and 'not stated' were merged into the 'other' category. Where denominator data was not required to calculate results, we used the entire dataset (May 2004-December 2008). Where denominator was required, for example to calculate the rate of infection in different ethnic groups, the dataset is restricted to cases in 2007 and 2008 only. Confidence intervals were calculated using standard methods [14].

\section{Results}

Between May 2004 and December 2008, testing for antenatal screening for $\mathrm{HbsAg}$ and $\mathrm{HbeAg}$ revealed 595 cases with HBV infection. Of these cases 130/595 (22\%) were previously known to be infected prior to their pregnancy. Of the 130 known cases, 108 had been diagnosed in a previous pregnancy within the study period. The majority, 347/595 (58\%), of cases were in the 25-34 years-old age groups (Table 1). A total of 407 
TABLE 1

Number of Birmingham residents diagnosed with hepatitis B on antenatal screening by age group, United Kingdom, May 2004-December 2008 ( $\mathrm{n}=595)$

\begin{tabular}{|l|c|}
\hline Age group in years & Number of hepatitis B cases \\
\hline$<20$ & 14 \\
\hline $20-24$ & 105 \\
\hline $25-29$ & 181 \\
\hline $30-34$ & 166 \\
\hline $35-39$ & 100 \\
\hline $40-44$ & 27 \\
\hline $45-49$ & 1 \\
\hline$>50$ & 1 \\
\hline Total & 595 \\
\hline
\end{tabular}

\section{TABLE 2}

Cases of hepatitis B diagnosed on antenatal screening, by ethnic group, Birmingham, United Kingdom,

May 2004-December $2008(n=595)$

\begin{tabular}{|c|c|c|}
\hline Ethnic group & $\begin{array}{l}\text { Number of } \\
\text { cases }\end{array}$ & $\begin{array}{l}\text { Percentage }(\%) \text { of cases } \\
\text { (95\% confidence intervals) }\end{array}$ \\
\hline Black African & 194 & $32.6(28.8-36.4)$ \\
\hline Pakistani & 146 & $24.5(21.1-28.0)$ \\
\hline Chinese & 67 & $11.3(8.7-13.8)$ \\
\hline Other $^{\mathrm{a}}$ & 51 & $8.6(6.3-10.8)$ \\
\hline White other ${ }^{b}$ & 31 & $5.2(3.4-7.0)$ \\
\hline Black other ${ }^{c}$ & 25 & $4.2(2.6-5.8)$ \\
\hline Bangladeshi & 23 & $3.9(2.3-5.4)$ \\
\hline Black Carribean & 17 & $2.9(1.5-4.2)$ \\
\hline Indian & 16 & $2.7(1.4-4.0)$ \\
\hline Asian other ${ }^{d}$ & 13 & $2.2(1.0-3.4)$ \\
\hline Not stated & 8 & $1.3(0.4-2.3)$ \\
\hline Not recorded & 3 & $0.5(0.0-1.1)$ \\
\hline White British & 1 & $0.2(0.0-0.5)$ \\
\hline
\end{tabular}

Other ethnic group than listed in the table.

White other than white British.

Black other than black African and black Caribbean.

Asian other than Bangladeshi, Indian, Chinese and Pakistani. of 595 cases $(68 \%)$ were in 'black African', Pakistani and Chinese ethnic groups (Table 2).

Regression analysis showed that there was a significant increase in the number of cases of hepatitis B being identified though antenatal screening from 106 cases in 2005 to 161 cases in $2008(p=0.037)$ (Table 3). This represents a $52 \%$ increase in cases in 2008 compared to 2005 with an average increase of 13.7 cases per year. The effect of ethnicity was also examined and although the number of cases in different ethnic groups was significantly different ( $p<0.001)$ the rate of change in the number of cases over time between ethnic groups was not.

HBeAg status was available on 585 of 595 cases. Patients with a positive $\mathrm{HBeAg}$ test have the highest infectivity and are most likely to transmit the virus to their child. A total of 67 of $585(11 \%)$ of cases were positive for $\mathrm{HBeAg}$. Of $\mathrm{HBeAg}$ positive cases, 42 of 67 $(63 \%)$ were in women of Chinese and Pakistani ethnicity (Table 4). Women with HBV infection of Chinese and Pakistani ethnicity were significantly more likely than other ethnicities to be $\mathrm{HBeAg}$ positive (chi-squared test $p$ valuero.001 and 0.025 respectively).

Rates and relative risks of infection were only calculated for cases in 2007 and 2008. In the two latter years, excluding cases occurring more than once due to repeated pregnancies resulted in a total of 268 cases of HBV infection. Women of 'black African', Pakistani, 'white other' and 'other' ethnicities all had a significantly higher rate of infection when compared to the England average rate of 350 per 100,000 antenatal tests (Table 5). Women of 'black African' and 'white other' ethnicity had markedly elevated risks (relative risk (RR): 11.25 and 5.87 respectively) compared to the England average. Women of 'white British' ethnicity had significantly lower relative risks of infection (RR: 0.01) but this represents a single case and this result should be interpreted with caution.

\section{TABLE 3}

Total number of hepatitis B cases identified by antenatal screening per year and percentage of total annual cases by ethnic group, Birmingham, United Kingdom, May 2004-December 2008 ( $\mathrm{n}=595)$

\begin{tabular}{|c|c|c|c|c|c|c|c|c|c|c|c|c|c|c|}
\hline \multirow[b]{2}{*}{ Year } & \multirow[b]{2}{*}{ Cases } & \multicolumn{13}{|c|}{ Percentage (\%) of total annual antenatal hepatitis B cases } \\
\hline & & $\begin{array}{c}\text { Black } \\
\text { African }\end{array}$ & Pakistani & Chinese & Other & $\begin{array}{l}\text { White } \\
\text { Other }\end{array}$ & $\begin{array}{l}\text { Other } \\
\text { Black }\end{array}$ & Bangladeshi & $\begin{array}{c}\text { Black } \\
\text { Caribbean }\end{array}$ & Indian & $\begin{array}{l}\text { Asian } \\
\text { Other }\end{array}$ & $\begin{array}{c}\text { Not } \\
\text { stated }\end{array}$ & $\begin{array}{c}\text { Not } \\
\text { Recorded }\end{array}$ & $\begin{array}{l}\text { White } \\
\text { British }\end{array}$ \\
\hline $2004^{\mathrm{a}}$ & 69 & 23 & 30 & 12 & 7 & 0 & 9 & 6 & 4 & 3 & 1 & 4 & 0 & 0 \\
\hline 2005 & 106 & 36 & 31 & 5 & 5 & 5 & 5 & 5 & 4 & 3 & 2 & 1 & 0 & 0 \\
\hline 2006 & 131 & 32 & 21 & 14 & 8 & 8 & 7 & 2 & 2 & 2 & 2 & 1 & 0 & 1 \\
\hline 2007 & 128 & 38 & 27 & 9 & 9 & 7 & 3 & 3 & 2 & 3 & 0 & 0 & 0 & 0 \\
\hline 2008 & 161 & 31 & 19 & 16 & 12 & 4 & 1 & 4 & 2 & 2 & 4 & 2 & 2 & 0 \\
\hline
\end{tabular}

a The year 2004 does not represent data for a complete year, as data were only collected from May to December 2004 . 
TABLE 4

Cases of hepatitis B virus infection, by hepatitis B e-antigen status and ethnic group, Birmingham, United Kingdom, May 2004-December $2008(n=595)$

\begin{tabular}{|c|c|c|c|c|c|}
\hline & HBeAg negative & HBeAg positive & Not recorded & Total & HBeAg positivity rate (\%) \\
\hline Chinese & 48 & 17 & 2 & 67 & $25^{\mathrm{a}}$ \\
\hline Black Caribbean & 13 & 4 & 0 & 17 & 24 \\
\hline Pakistani & 117 & 25 & 4 & 146 & $17^{\mathrm{a}}$ \\
\hline Other & 43 & 8 & 0 & 51 & 16 \\
\hline Asian other ${ }^{b}$ & 11 & 2 & 0 & 13 & 15 \\
\hline Black other ${ }^{c}$ & 22 & 3 & 0 & 25 & 12 \\
\hline White other ${ }^{d}$ & 29 & 2 & 0 & 31 & 6 \\
\hline Bangladeshi & 21 & 1 & 1 & 23 & 4 \\
\hline Black African & 186 & 5 & 3 & 194 & 3 \\
\hline Indian & 16 & 0 & 0 & 16 & 0 \\
\hline Not stated & 8 & 0 & 0 & 8 & 0 \\
\hline Not recorded & 3 & 0 & 0 & 3 & 0 \\
\hline White British & 1 & 0 & 0 & 1 & 0 \\
\hline Total & 518 & 67 & 10 & 595 & 11 \\
\hline
\end{tabular}

HBeAg: hepatitis B e-antigen.

a Significantly higher positivity than average, chi-squared p<0.05.

b Asian other than Bangladeshi, Indian, Chinese and Pakistani. Black other than black African and black Caribbean.

d White other than white British.

\section{Discussion}

The number of cases of hepatitis B diagnosed through antenatal screening in Birmingham and Solihull increased over the period 2004-2008. However, as limited historical denominator information is available it is impossible to distinguish whether this increase is due to increased numbers of women attending antenatal screening from high risk groups or whether this represents an actual increase in the prevalence of infection.

The greatest burden of HBV infection in pregnant women cared for in Birmingham and Solihull is in women of 'black African', 'white other' and Pakistani ethnicity. Of these ethnicity categories, the rate of infection is greatest in 'black African' women at 3,938 per 100,000 or approximately $4 \%$. This is a similar figure compared to estimates of HBV prevalence in intermediate prevalence countries [15]. It is also relatively consistent with a study in Liverpool, England that found the prevalence of HBsAg in people aged 20-44 years-old and born in Somalia to be $9.4 \%$ [16]. Having considered what is known about migration patterns in Birmingham, we hypothesise that the high rate of infection in women of 'white other' at 2,054 per 100,000, approximately $2 \%$, reflects infection in recent immigrants from Eastern Europe where HBV prevalence is of the order of $2-7 \%$ [15]. However, more accurate information about nationality or country of birth is required to confirm this hypothesis.
In the 'other' ethnicity category, which accounted for a rate of infection of 671 per $100,000,48 \%$ were of Chinese ethnicity. We hypothesise that the HBV infection rate in Chinese women may be substantially higher than estimated, due to the relatively small Chinese population in Birmingham and Solihull. However, the lack of denominator data for this ethnicity category limited our ability to analyse this directly.

The higher burden of $\mathrm{HBeAg}$ positivity in Chinese and Pakistani women suggests that clinicians should be particularly aware of the higher risks of vertical transmission in these groups and the greater likelihood of the need for neonatal immunoglobulin treatment.

Currently, screening for hepatitis B infection only occurs as part of antenatal infectious disease screening in order to reduce the mother to child transmission of HBV infection. Health services in areas with large 'black African', 'white other' and Pakistani populations may wish to consider introducing targeted testing/case finding for HBV in people from these ethnic groups, for example as part of new patient assessments at general practices. Wider testing of these high risk groups is important as antenatal screening misses the larger proportion of the population made up of non-pregnant women and men. Current guidelines for pre-exposure HBV vaccination do not include recommendations for vaccination based on ethnicity or being born in a country with a high HBV prevalence [1]. It is recommended, however, that some people travelling to high 
TABLE 5

Ethnic group rate and relative risk, compared to the England average, of antenatal hepatitis B virus infection, United Kingdom, January 2007-December 2008 (n=268)

\begin{tabular}{|c|c|c|}
\hline Ethnic group & $\begin{array}{l}\text { Rate of hepatitis B virus } \\
\text { infections per } 100,000 \\
\text { pregnant women ( } 95 \% \\
\text { confidence interval) }\end{array}$ & $\begin{array}{c}\text { Relative risk } \\
\text { (95\% confidence } \\
\text { interval) }\end{array}$ \\
\hline Reference $^{\mathrm{a}}$ & 350 & Reference \\
\hline White British & $3.9(0.1-195.3)^{b}$ & $0.01(0.00-0.56)^{b}$ \\
\hline White other ${ }^{c}$ & $2,054.2(966.1-4,368.0)^{\mathrm{b}}$ & $5.87(2.76-12.48)^{\mathrm{b}}$ \\
\hline Indian & $411.1(144.2-1,172.1)$ & $1.17(0.42-3.35)$ \\
\hline Pakistani & $815.1(562.8-1,180.5)^{b}$ & $2.33(1.61-3.37)^{b}$ \\
\hline Bangladeshi & $641.0(253.5-1,614.9)$ & $1.83(0.73-4.61)$ \\
\hline Black Caribbean & $557.9(202.8-1,535.1)$ & $1.59(0.58-4.39)$ \\
\hline Black African & $3,938.4(2,888.9-5,369.2)^{b}$ & $11.25(8.25-15.34)^{b}$ \\
\hline Other & $676.3(363.9-1,256.9)^{b}$ & $1.93(1.04-3.59)^{b}$ \\
\hline
\end{tabular}

a England average [7].

b Significantly different at 0.05 level from the England average.

White other than white British.

prevalence countries should receive vaccination prior to travel. The high prevalence rates amongst 'black African', 'white other' and Pakistani pregnant women found in this study provide a strong argument to reconsider targeted testing and immunisation for high risk ethnic groups. There is also evidence to show that selective vaccination of high risk groups with similar prevalence rates to groups identified in this study such as genitourinary medicine (GUM) clinic attendees, prisoners and dialysis patients is cost effective $[17,18]$.

The most important limitation to this study is the lack of historical and linked ethnicity data for pregnant women. This prevented us from assessing trends over time to estimate the rate of increase in different ethnic groups. The ethnicity categories also differed slightly between the case data and the denominator data meaning that some ethnicity categories, notably Chinese, were merged with other categories in the final part of the analysis. We also did not have information on the country of birth for cases. This is likely to be a significant factor in determining the likelihood of HBV infection as the rate of infection for women of later generation immigrants is likely to approach that of the white British population, as is seen for many other infectious diseases, as opposed to recent immigrants who are more likely to carry the risk of the country they have moved from.

Despite these limitations, this study shows that the routine collection of ethnicity data can identify latent health inequalities that were previously unnoticed or only supported by anecdotal evidence. Healthcare organisations should continue to improve ethnicity recording to ensure that it is complete, accurate and consistent using nationally agreed categorisation.

Further research to corroborate these findings and quantify the burden of HBV infection in pregnant women of Chinese ethnicity is required as is research to examine the effect of country of birth on the rate of infection.

Organisations that serve populations with a high or increasing proportion of women originating from areas of the world with high prevalence of HBV infection should anticipate an increasing need for perinatal and postnatal prophylaxis to children born to infected mothers. This will be in addition to the increasing need for harm reduction measures and the treatment of patients with HBV infection and its sequelae. Healthcare providers should be particularly aware of the financial and human resource implications of an increasing rate of $\mathrm{HBV}$ infection in pregnant women which is likely to reflect the trend in the population as a whole. 


\section{References}

1. Salisbury D, Ramsay M, Noakes K, editors. Immunisation Against Infectious Disease. London: The Stationary Office. 2006.

2. Health Protection Agency (HPA). Hepatitis B. Notifications for England and Wales 1990-2003. London: HPA. [Accessed 22 Jun 2012]. Available from: http://www.hpa.org.uk/ Topics/InfectiousDiseases/InfectionsAZ/HepatitisB/ EpidemiologicalData/hepbNotAge/

3. Gilson RJ, De Ruiter A, Waite J, Ross E, Loveday C, Howell DR et al. Hepatitis $B$ virus infection in patients attending a genitourinary medicine clinic: Risk factors and vaccine coverage. Sexually Transmitted Infect. 1998;74(2): 110-5.

4. Uddin G, Shoeb D, Solaiman S, Marley R, Gore C, Ramsay M, et al. Prevalence of chronic viral hepatitis in people of south Asian ethnicity living in England: the prevalence cannot necessarily be predicted from the prevalence in the country of origin. J Viral Hepat. 2010;17(5):327-35

5. British Association of Sexual Health and HIV (BASHH). United Kingdom National Guideline on the Management of the Viral Hepatitides A, B \& C 2008. London: BASHH. 2008. [Accessed 22 Jun 2012]. Available from: http://www.bashh.org/ documents/1927

6. Health Protection Agency. Surveillance of markers of infection detected in antenatal samples tested by NHS Blood and Transplant (NHSBT): England, 2008. Health Protection Report. 2009;3(12):16-21

7. Boxall E, Skidmore S, Evans C, Nightingale S. The prevalence of hepatitis $B$ and $C$ in antenatal populations of various ethnic origins. Epidemiol Infect. 1994;113(3):523-8.

8. Elefsiniotis IS, Glynou I, Zorou I, Magaziotou I, Brokalak $\mathrm{H}$, Apostolopoulou E et al. Surveillance for hepatitis B virus infection in pregnant women in Greece shows high rates of chronic infection among immigrants and low vaccinationinduced protection rates: Preliminary results of a single centre study. Euro Surveill. 2009;14(9): pii=19132. Available from: http://www.eurosurveillance.org/ViewArticle. aspx?Articleld $=19132$

9. Bonura F, Sorgi M, Perna AM, Puccio G, Tramuto F, Cajozzo C et al. Pregnant women as a sentinel population to target and implement hepatitis B (HBV) vaccine coverage: a three-year survey in Palermo, Sicily. Vaccine. 2005;23(25):3243-6.

10. Tang KY, Chan T, Fenton KA, Gilson RJ. Hepatitis B in the Chinese community in Britain. BMJ. 1996;312(7029):507.

11. Tawk HM, Vickery K, Bisset L, Selby W, Cossart YE; Infection in Endoscopy Study Group. The impact of hepatitis B vaccination in a Western country: recall of vaccination and serological status in Australian adults. Vaccine. 2006;24(8):1095-106.

12. Stengel B, Saurel-Cubizolles MJ, Kaminski M. Pregnant immigrant women: occupational activity, antenatal care and outcome. Int J Epidemiol. 1986;15(4):533-9.

13. Office for National Statisics (ONS). Guidance and methodology; Ethnic group. [Accessed 22 Jun 2012]. Available from: http:// www.ons.gov.uk/ons/guide-method/measuring-equality/ equality/ethnic-nat-identity-religion/ethnic-group/index.html

14. Pencheon D, Guest C, Melzer D, Gray JAM, editors. Oxford Handbook of Public Health Practice 2nd edition. Oxford: Oxford University Press. 2006.

15. Centers for Disease Control and Prevention. CDC Health Information for International Travel 2012. New York: Oxford University Press; 2012. [Accessed 22 Jun 2012]. Available from: http://wwwnc.cdc.gov/travel/yellowbook/2012/chapter-3infectious-diseases-related-to-travel/hepatitis-b.htm

16. Aweis D, Brabin BJ, Beeching NJ, Bunn JE, Cooper C, Gardner $\mathrm{K}$ et al. Hepatitis B prevalence and risk factors for $\mathrm{HBsAg}$ carriage amongst Somali households in Liverpool. Commun Dis Public Health. 2001;4(4):247-52.

17. Mangtani $P$, Hall AJ, Normand CE. Hepatitis B vaccination: the cost effectiveness of alternative strategies in England and Wales. J Epidemiol Community Health. 1995;49(3):238-44

18. Williams JR, Nokes DJ, Anderson RM. Targeted hepatitis B vaccination - a cost effective immunisation strategy for the UK? J Epidemiol Community Health. 1996;50(6):667-73. 